\title{
CLAVES PARA ENTENDER LA POLIITICA MIGRATORIA MEXICANA EN TIEMPOS DE LÓPEZ OBRADOR
}

\author{
Leticia Calderón CHELIUS ${ }^{1}$
}

RESUMEN: El objetivo de este artículo es ofrecer una visión panorámica de la política migratoria de los primeros ańos de gobierno del presidente López Obrador en México. Mostrar que más allá de la retórica humanitaria con que arrancó su gobierno respecto a los inmigrantes, la visión gubernamental del ejecutivo no tiene en su mapa político a este sector, lo que explica las decisiones pragmáticas que dicho gobierno ha tomado en su difícil relación en el tema con Estados Unidos. Los múltiples hechos políticos que se han sucedido uno tras otro de manera vertiginosa en un corto tiempo en el poder, dada la decisión de cambiar de manera radical el tipo de gobierno que México ha tenido por años, explican a su vez, decisiones que van más allá del propio flujo migratorio.

PALABRAS CLAVE: política migratoria; México; López Obrador; derechos humanos; relación bilateral.

\section{KEYS TO UNDERSTANDING MEXICAN IMMIGRATION POLICY IN THE TIMES OF LÓPEZ OBRADOR}

ABSTRACT: The purpose of this article is to provide an overview of the immigration policy of the early years of President López Obrador's government in Mexico. It shows that in addition to the humanitarian rhetoric with which his government began in relation to immigrants, the government's view of the executive does not have this sector in its political map, which explains the pragmatic decisions that this government has made in its difficult

\footnotetext{
1 Instituto Mora, Ciudad de Mexico - Mexico. Profesora e investigadora. ORCID: https://orcid.org/0000-00020221-7591.1calderon@mora.edu.mx.
} 
relationship in the matter with the United States. The multiple political events that occurred one after the other in a dizzying way in a short period of government, given the decision to radically change the type of government that Mexico had for years, decisions that go beyond the migratory flow itself.

KEYWORDS: immigration policy; Mexico; López Obrador; human rights; bilateral relationship.

El 1 de diciembre de 2018, Andrés Manuel López Obrador tomó el poder como presidente de México. $\mathrm{AMLO}^{2}$ llegó a la presidencia luego de una larga trayectoria desde la oposición política contra la élite en el poder representada por el PRI y el PAN ${ }^{3}$ quienes se alternaron en el control del gobierno a nivel federal los últimos 20 ańos. La amplia mayoría de votos que obtuvo la opción catalogada como de izquierda por sus posturas anti establishment le dio a López Obrador el control de la Cámara de Diputados y la presencia contundente de su partido en el Senado, además, obtuvo gubernaturas y multiplicó su presencia en estados del país donde nunca antes había ganado un partido de izquierda. Sus oponentes quedaron muy por detrás de su número de votos y algunos, incluso en riesgo de desaparecer por el bajo número de votantes y por los fraudes electorales que presuntamente cometieron para llegar al poder cuando fueron gobierno y que ponen en riesgo sus registros como partidos políticos.

Aquel 1 de diciembre de 2018 el nuevo presidente se presentó al pueblo de México con un discurso radicalmente distinto al de sus antecesores respecto a la mayoría de los temas públicos. En el caso de la migración internacional, su discurso recuperó lo que los analistas más críticos habían repetido durante años. López Obrador dijo contundentemente "México exige un buen trato a otros países -especialmente Estados Unidos, pero no respeta a los extranjeros que cruzan nuestro territorio nacional", "Es tiempo de hacernos responsables de las razones que expulsan a millones de mexicanos a vivir fuera del país" y "México recuperara su tradición hospitalaria y generosa con quienes buscan refugio" entre otras muchas ideas dichas en el discurso inaugural de su gestión como presidente de México. Esas palabras suponían un golpe de timón de lo que fue la política migratoria mexicana durante ańos y anunciaban un cambio de 180 grados respecto a la visión de seguridad, contención y restricción que

\footnotetext{
2 AMLO Por sus iniciales Andrés Manuel López Obrador

3 Partido Revolucionario Institucional y Partido Acción Nacional respectivamente
} 
había tenido la política migratoria mexicana hacia los extranjeros que cruzan el país rumbo a Estados Unidos desde hace décadas (CALDERÓN CHELIUS, 2018a). Parecía el inicio de una época dorada para los derechos humanos de los migrantes internacionales, pero para sorpresa de todos, ocurrió lo contrario.

Para entender la política migratoria del gobierno mexicano dirigido por López Obrador, no basta con centrarse en analizar las circunstancias específicas del flujo y la movilidad humana. Tampoco en discutir el lugar geográfico que México ocupa como principal corredor migratorio del mundo (frontera con Estados Unidos), ni mucho menos, querer encasillar al país en la dinámica asimétrica bilateral con el país más rico del mundo. Es necesario ampliar la mirada y ver panorámicamente el lugar que el tema migratorio ocupa para el proyecto de nación que dicho gobierno persigue. Por eso, aunque desde el inicio de su gobierno López Obrador haya hecho mención a la migración en México, la realidad es que el tema no le es cercano. A diferencia del profundo conocimiento que el presidente mexicano tiene de la realidad del país, su cercanía con las comunidades más pobres y de su andar por el territorio nacional como pocos, el tema migratorio es un tema relativamente nuevo en su agenda. López Obrador ha sostenido por años que "la mejor política exterior es la política interior" (LÓPEZ OBRADOR, 2017), lo que explica su resistencia a incluir en sus actividades el realizar viajes al extranjero o mantener contacto con otros gobiernos y comunidades de manera directa y cotidiana. Como activista y candidato a la presidencia hizo lo mismo y pocas veces se involucró con lo extranjero, por lo que, salvo un viaje internacional de acercamiento a las comunidades mexicanas en Estados Unidos a inicios de 2017, su contacto directo con el tema migratorio se ha dado a través de colaboradores directos, asesores o liderazgos históricos de migrantes mexicanos que lo apoyan desde hace décadas. Su visión de "lo migratorio" por tanto, se concentra en ese sector del México marginado que decidió emigrar a falta de oportunidades en su propio país, lo que encaja perfectamente con su análisis y perspectiva del cambio que se propone hacer. Un dato que no es menor es el hecho de que esta perspectiva le atrajo la simpatía de enormes sectores de esos mexicanos autoexiliados durante décadas. El reconocimiento de las condiciones de pobreza, desigualdad y violencia como causas del éxodo mexicano y su compromiso de cambiar esas situaciones, le sirvieron a él y a su partido MORENA ${ }^{4}$, para obtener la mayoría de los votos de los mexicanos que viven fuera del país y quedar muy por encima de lo que otros candidatos recibieron (LI NG; SERRANO, 2018). Dicho apoyo no queda solo en votos ya

\footnotetext{
4 Movimiento de Regeneración Nacional
} 
que el flujo de remesas enviadas por los trabajadores mexicanos desde el extranjero se ha mantenido constante e incluso, sorprendentemente, creció pese a la crisis económica en Estados Unidos a causa del COVID-19. Esto explica que cuando López Obrador habla de la migración se refiera a "los migrantes mexicanos" a quienes incluso llama héroes y por el perfil de origen de la mayoría, los incluye en su noción de pueblo y como parte de la clase trabajadora que conoce profundamente. Aun así hay que decir que este contacto es más retórico que de sustancia pues ha habido pocos apoyos directos a esa comunidad de casi 12 millones de mexicanos radicados principalmente en Estados Unidos. Es su promesa de cambio y la intención explicita de combatir la corrupción lo que le atrae el apoyo de la mayoría de dicha comunidad.

Más allá de esta comunidad de mexicanos radicados en el extranjero, López Obrador no conoce con mayor detalle otras facetas dentro del proceso migratorio, como es el tránsito migratorio o los extranjeros que llegan para establecerse en el país en números crecientes ${ }^{5}$, lo que implica que no los ha considerado como parte integral de la estrategia de cambio que pretende hacer en el país a pesar de tener entre sus aliados más cercanos y consejeros a algunos personajes vinculados a esta dinámica migratoria, como es el caso del sacerdote Alejandro Solalinde, reconocido activista promigrantes (RUIZ PARRA, 2011) entre otros. Entender este punto es central para poder seguir los vaivenes de la política migratoria mexicana posteriores a la toma de poder del presidente López Obrador y poder ver más allá de su discurso inaugural.

\section{Las piezas del rompecabezas, las caravanas}

A finales de 2018 se dio un evento que causó gran revuelo a nivel nacional e internacional. Se trató de la caminata masiva de personas provenientes principalmente de Centro América, como de los países Honduras, El Salvador, Guatemala y sobre todo Nicaragua. Este grupo de personas buscaba cruzar la frontera sur de México para llegar a la frontera norte del país y cruzar a Estados Unidos. En el camino de lo que se definió como un éxodo casi bíblico, quedó claro que si bien estas no eran las primeras caravanas de migrantes que cruzaban de manera masiva el país, ya que anteriormente se dieron múltiples "performances" que buscaban visibilizar el duro camino del tránsito migratorio a través de México -caravanas de madres buscando a sus hijos, el viacrucis migratorio

\footnotetext{
En México la idea de las comunidades de extranjeros se suele ubicar en el exilio español que llegó al país en los años 40's y el exilio sudamericano de los años 70s del siglo XX. Esto ha construido una narrativa que encasilla la problemática migratoria a un lugar historico lejano al presente (CALDERÓN CHELIUS, 2018b).
} 
durante Semana Santa-, la realidad es que esta experiencia fue inédita para la inmensa mayoría de los mexicanos que siguieron el evento con gran interés, un tanto por la sorpresa, otro tanto por la inmensa difusión que los medios de comunicación le dieron al suceso. Un elemento muy importante para entender este evento es que ocurrió en un momento de una especie de "vacío político en México". Esto se debe a que mientras que la elección presidencial en la que ganó el candidato López Obrador se llevó a cabo el 1 de julio, su toma de posesión como presidente constitucional fue hasta el 1 de diciembre -de acuerdo a la ley-, por lo que durante ese semestre de 2018, el presidente en funciones era el saliente Enrique Peńa Nieto, mientras que López Obrador ya era presidente de facto y ejercía como tal, sobre todo por el enorme respaldo electoral con que alcanzó el poder $^{6}$. Esto intensificó el cruce de mensajes de las distintas autoridades que, a la postre, explican por qué la marcha masiva de migrantes que demandaba el libre tránsito migratorio doblegó a la férrea policía migratoria mexicana.

A días de concluir su gobierno, Peña Nieto se limitaba a señalar que quienes planearan cruzar por México debían ceñirse las normas migratorias, las cuales son casi imposibles de cumplir para la inmensa mayoría de los trabajadores migrantes de origen más bien humilde, dada la cantidad de requisitos que las leyes mexicanas exigen. Por su lado, López Obrador enviaba mensajes de bienvenida y anunciaba que durante su sexenio serían respetados todos aquellos que desearan llegar al país a contribuir a su desarrollo. Esto provocó una reacción de lo que se conoce como, "efecto llamada" que convocó a un número aún mayor de personas que vieron en los mensajes dados por la ambigüedad entre ambas autoridades presidenciales, la oportunidad para cruzar y transitar de manera segura el territorio mexicano (CALDERÓN CHELIUS, 2019). Al llegar a la frontera, las escenas de cierre parcial del cruce migratorio no se hicieron esperar y hubo gases, helicópteros, perros policías y mucha autoridad policial restringiendo el cruce fronterizo, incluso violentamente. Los videos y fotos circularon de inmediato por todo el mundo, lo que obligó a la autoridad mexicana a ceder y permitir que entraran al territorio mexicano un grupo que en su punto más alto alcanzó las 20000 personas. Así, a lo largo de un par de semanas, personas migrantes en lo individual y familias enteras caminaron por territorio mexicano recibiendo en muchos casos el apoyo de los pobladores de las comunidades donde iban pasando. En algunas localidades los pobladores se desbordaron en ayudas de agua, comida, ropa e incluso apoyos como carriolas y enseres para quienes traían niños menores (VARELA, 2019). Esta primera caravana se fue

${ }_{6}$ López Obrador (MORENA) obuvo 53.2\% de los votos, Ricardo Anaya (PAN), 22.27\%, José Antonio Meade (PRI) $16.40 \%$ y Jaime Rodríguez (independiente) $5.23 \%$. 
diseminando al caminar por el país, no obstante, un número importante de varios miles de personas llegó a la ciudad fronteriza de Tijuana donde fueron detenidos por la autoridad estadounidense que aplicó con severo rigor la orden de no cruzar a su país. Este episodio fue políticamente muy costoso para el gobierno mexicano porque el presidente Donald Trump lo aprovechó para atacar a la autoridad presidencial mexicana acusándola de permitir el cruce migratorio para "invadir Estados Unidos".

Si se sigue este relato, se puede observar que en paralelo a la caminata de esta caravana (finales de 2018) se dio la toma de poder del presidente electo, López Obrador, lo que explica que el tema de alguna manera "se impuso" en la agenda política de López Obrador más allá de tenerlo incluido en su lista de preocupaciones y promesas.

\section{La esfera internacional}

Decir que la agenda migratoria "se impuso" al gobierno de López Obrador no es del todo cierto si se consideran otras variables. Durante décadas México ha sido un firmante recurrente de los tratados internacionales en la materia. Desde la Convención Internacional sobre la protección de los derechos de todos los trabajadores migratorios y sus familiares de 1990, que entró en vigor en 2003 con la firma de más de 50 países, los distintos gobiernos mexicanos han sido entusiastas firmantes e incluso entre los impulsores más decididos. No obstante, el documento internacional de mayor relieve que el país ha firmado es el Pacto mundial para la migración segura, ordenada y regular, que junto con El Pacto sobre Refugiados, ambos firmados en diciembre de 2018, definen un nuevo marco jurídico internacional para la gobernanza migratoria. Lo interesante es que ambos documentos se firmaron a escasos días de la toma de poder del nuevo gobierno, El Pacto de migración, el 11 y 12 de diciembre y el Pacto sobre Refugiados, el 17 de diciembre de 2018. Esto implica que el gobierno mexicano encabezado por López Obrador decidió hacer suyo un proyecto que durante varios años encabezó precisamente la cancillería mexicana del gobierno saliente. Dada la nueva retórica del nuevo gobierno y la intención explicita de romper con el régimen pasado, los recién llegados al poder podrían haber pospuesto la firma de ambos tratados, como en su momento lo hicieron otros países de la región latinoamericana. Sin embargo, de manera absolutamente opuesta, el nuevo gobierno mexicano, a través de su cancillería, mantuvo el liderazgo ante la firma y eventual puesta en marcha de los acuerdos a que ambos pactos comprometen a las partes firmantes. El detalle no es menor y es una pieza muy importante para entender el complejo rompecabezas 
político frente a la dinámica migratoria, que para México es fundamental por su condición de país de alta expulsión migratoria, de tránsito y de manera creciente como destino de personas migrantes que buscan establecerse en el país.

A este crucigrama se puede sumar el compromiso explícito del gobierno mexicano de hacer suya la Agenda 2030 de las Naciones Unidas como metas concretas por cumplir. Esto muestra que más allá de la voluntad e interés del presidente en ciertos temas y aparentemente no en otros, hay otros actores políticos, en este caso la cancillería, es decir, la Secretaría de Relaciones Internacionales, que mantiene una dinámica que vincula el país a distintos procesos y tiene compromisos internacionales que se decidió mantener, incluso con un cambio tan drástico como el que se prometió hacer. Es útil mencionar que la Secretaría de Relaciones Exteriores dirige Marcelo Ebrard, a quien se califica públicamente como la mano derecha de López Obrador por la cercanía política y alianza que han mantenido desde hace años, incluso en los momentos más duros para ambos y cuando unos años antes, algunos los consideraban neutralizados políticamente. Su regreso al poder, especialmente el de Ebrard, es una especie de ave fénix resurgiendo de sus propias cenizas.

Por tanto, más allá de que la migración internacional no sea un tema de la agenda más cercana a López Obrador y en su caso se centre sobre todo en los mexicanos que radican en el extranjero, ante quien declara palabras de una alta estima, aprecio y reconocimiento en cuanta oportunidad tiene, eso no quiere decir que la dinámica de la inmigración (tránsito y destino) no sea parte de las prioridades del gobierno mexicano aunque no lo sea en voz del presidente, sino en una agenda que se ubica más en la esfera internacional y que coordina Marcelo Ebrard como el actor político relevante para entender este tema.

\section{El plan de desarrollo mesoamericano}

El cambio radical de discurso político inició desde el primer día del nuevo gobierno (diciembre 2018). Desde el primer día se oyeron mensajes completamente distintos a los de los anteriores gobiernos e incluso, el estilo, la personalidad y la forma de establecer contacto con las masas de parte del presidente estableció una nueva dinámica. En el caso de la migración quedó claro que una cosa eran los "héroes migrantes", mexicanos que radican en el exterior y que con el envío de remesas a sus familias contribuyen de una manera absolutamente fundamental a la economía mexicana. Otra muy diferente es la inmigración, sean de quienes buscan refugio como de quienes van de paso en busca del país del norte (SOLICITUDES..., 2015). Ante esta disociación, la salida "salomónica" 
ante el tema se dio a través de hacer parte de la agenda gubernamental, una propuesta que llegó desde la esfera de un organismo internacional. Se trata del Plan de Desarrollo Integral Mesoamericano que elaboró la CEPAL y que consiste en buscar potenciar una dinámica de integración en la región de Centroamérica (países del triángulo del Norte, Guatemala, El Salvador y Honduras) a partir de generar un desarrollo basado en coordenadas como inversión, bienestar social y "gestión integral del ciclo migratorio con seguridad humana". El plan ofrecido por la CEPAL en la voz de su presidenta, la Dra. Alicia Bárcenas, permitía subsanar dos objetivos que el nuevo gobierno mexicano no tenía como sus temas más fuertes, la relación con los gobiernos de Centroamérica y la atención al flujo migratorio a través del país. Además, con este plan liderado por la propia CEPAL, López Obrador se mantenía en su principio de "la mejor política exterior es la política interior" porque ofrecía apoyar el desarrollo de los países expulsores de migrantes reconociendo que la pobreza, la violencia y la desigualdad estructural, son los gérmenes de la migración forzada y que por tanto, entraban perfecto en la idea esgrimida por AMLO de que "la migración lo sea por deseo y no por necesidad", tanto para los mexicanos como pudiera llegar a ser para los centroamericanos. La propuesta era simple, apoyar el desarrollo de la región centroamericana como elemento que llevaría a retener a las personas en sus lugares de origen y, por tanto, a disminuir el flujo, lo que, si bien puede ser una idea interesante, es un proyecto a muy largo plazo y el Plan elaborado por la CEPAL tiene etapas que apenas están en proceso. Hasta el momento, dicho Plan quedó en un aporte en varios miles de dólares que el gobierno mexicano dio tanto al gobierno de El Salvador en la persona de su presidente, Nayib Bukele, quien tomó posesión el 1 de junio de 2019, al de Honduras, presidente Juan Orlando Hernández (2014), y al de Guatemala, presidente Alejandro Guammattei (14 de enero de 2020). Es importante hacer notar que por lo menos dos de los tres presidentes mencionados tomaron posesión de sus respectivos cargos casi a la par que López Obrador, lo cual constituye un nuevo escenario regional. La propuesta de atender a la migración desde Centroamérica a partir de fortalecer su potencial y fomentar su desarrollo fue muy bien recibida por la opinión pública mexicana, aunque no faltaron las voces críticas que acusaron al gobierno mexicano de que a través de esta propuesta se preservaba la relación de "hermano mayor" de México respecto al resto de los países de la región, una especie de imposición mexicana que históricamente se atribuye a la dinámica entre estas naciones. De alguna manera la interacción entre los distintos gobiernos de esta área no avanzó mucho más, dadas las enormes problemáticas internas de cada país y en el caso de México, la centralidad en los proyectos que son eje del desarrollo que 
se busca en el territorio nacional, como es el programa de reforestación masiva "sembrando vidas" y la eventual construcción del "tren maya" en la región de la península de Yucatán, que no lograron vincularse a los proyectos que se llevan a cabo en los países socios.

\section{¿Qué hacemos con los inmigrantes?}

El gobierno mexicano que encabeza López Obrador tiene una perspectiva de izquierda en gran parte de sus decisiones y proyectos. El presidente no titubea en declararse a favor de las minorías más pobres e históricamente marginadas, en el tema migratorio, sin embargo, su política ha sido de corte restrictivo y policiaco. Si bien no empezó con esa intención, las circunstancias hicieron que se diera este giro.

Al inició del año 2019 y en pleno ejercicio del poder presidencial, se experimentaba un avance vertiginoso en los temas de la agenda política prevista por el nuevo gobierno. En el tema migratorio, sin embargo, hacia finales de enero de ese año en que recién había tomado el poder la nueva presidencia, se organizó una nueva caravana de migrantes desde Centroamérica y ahí empezaron a aflorar las contradicciones. Al inicio de la llegada del nuevo flujo de personas migrantes, el nuevo gobierno (apenas un mes en el poder), buscó presentar una actitud totalmente distinta a la de todos los gobiernos anteriores. En el cruce fronterizo entre México y Guatemala se desplegó un equipo de distintas dependencias dedicadas a atender el tema migratorio (Instituto Nacional de Migración INM, la Comisión Mexicana Ayuda al Refugiado, COMAR) junto con dependencias internacionales como la OIM y ACNUR, quienes dieron la bienvenida a las personas migrantes que cruzaban la frontera y se les otorgaban visas humanitarias temporales para permanecer en el país (con vigencia de un año). La recepción tan cálida por parte de las autoridades impactó enormemente a las personas que llegaban lo mismo que a la opinión pública, porque en lugar de restringir el paso, les daban literalmente la bienvenida a México. Sin embargo, la llegada masiva y la sobredemanda de trámites por parte de la población que seguía llegando desbordó a las instituciones encargadas de verificar la identidad jurídica de las personas, se detuvo la entrega de visas humanitarias y el proyecto cerró al cabo de un corto tiempo (FERNÁNDEZ DE LA REGUERA; GANDINI; GUTIÉRREZ LÓPEZ; NARVÁES GUTIÉRREZ, 2019).

En ese mismo marco y al poco tiempo (dos meses después), se organizó otro grupo que buscaba conformar una nueva caravana como la que se dio en 2018 -la madre de todas las Caravanas, se decía-, sin embargo, pese a que las per- 
sonas lograron cruzar a territorio mexicano y transitar por el país, no hubo ya la recepción afectuosa y solidaria de la población mexicana -salvo casos ejemplares-. Incluso se empezaron a verificar actitudes de xenofobia de parte de algunas personas y comunidades, sobre todo en la frontera sur donde la autoridad migratoria mexicana trató de mantener de manera forzada a los migrantes que continuaban entrando al país, ya sin el respaldo de la autoridad migratoria mexicana.

Un punto a considerar es el hecho de que a la par del proceso migratorio, el nuevo gobierno presentaba cada día un nuevo proyecto y declaraba una nueva embestida contra sus adversarios políticos, lo mismo que mantenía un enfrentamiento con los poderes fácticos que hacen una especie de gobierno sombra frente al gobierno -los medios de comunicación, las grandes fortunas, los liderazgos de oposición-. En ese contexto iniciaron manifestaciones de grupos de clase media y media alta contra el nuevo gobierno y lo mismo que muestras masivas de respaldo popular a favor de López Obrador y su gestión. En este contexto el tema migratorio era prácticamente irrelevante salvo alguna mención xenófoba entre los críticos al gobierno que calificaban de incapaz al presidente por "abrirle la puerta a los extranjeros pobres". Un hecho que es indispensable de considerar porque permite entender el momento político y social en que se daba todo este proceso, fueron las movilizaciones masivas que se dieron como resultado de uno de los temas centrales de la vida pública mexicana, la campaña de combate contra el robo de gasolina de los gasoductos que se inició abiertamente a finales de 2018, pero alcanzó su clímax los primeros meses de 2019 (este robo de combustible es conocido en México como huachicol). Este proceso movilizó a la población en todo el país porque la estrategia consistió en cerrar literalmente los ductos de gasolina a lo largo de todo el territorio nacional para detectar los robos y las complicidades desde la propia empresa encargada del petróleo en México, PEMEX. Esto implicó que por varias semanas e incluso meses en algunas regiones, no hubo gasolina o estuvo sumamente restringida su venta, lo que paralizó sectores de transporte y afectó la movilidad pública e individual. Pese a lo drástico de la medida y las críticas constantes desde los medios de comunicación, la estrategia recibió un apoyo popular sin precedentes y un respaldo mayoritario al presidente, incluso de los sectores que al inicio lo criticaron duramente. La campańa se vivió como una especie de gesta popular para recuperar el control de la empresa petrolera que ha sido por años la fuente de recursos más importante del país.

La importancia de relatar este acontecimiento es que muestra el ambiente político a nivel nacional donde el tema migratorio, aún con su importancia, se percibía como algo lejano para la población mexicana, mientras que la lucha 
contra el robo de gasolina era un tema central y, sobre todo, un momento cumbre para la toma de poder real del nuevo gobierno.

\section{Trump amenaza, López Obrador cede.}

El 30 de mayo de 2019 Donald Trump lanzó un tweet al ciberespacio. Desde su campaña presidencial en 2016 el presidente estadounidense acostumbró a los mexicanos a sus tweetsiracundos e irrespetuosos, por lo que este nuevo mensaje era uno más de la larga lista, con un agravante: se lo dirigía al nuevo presidente que tenía apenas 6 meses en el poder y el cual se encontraba de lleno metido en una batalla de intercambios de culpas y ajustes a la conducción de lo que había hecho la élite política mexicana durante años. El tweet de Trump era una amenaza directa y contundente a la economía mexicana que, además, se salía del guión político que López Obrador se había dado, para redefinir la relación política entre la presidencia mexicana y los grupos de poder nacionales. A partir del 10 de junio Estados Unidos impondría una trifa arancelaria a todos los productos que llegaran a Estados Unidos procedentes de México, en tanto siguieran cruzando inmigrantes 'ilegales' a ese país. Dicha tarifa se iría incrementando hasta un $25 \%$ en tanto dicho flujo 'sin papeles' no se detuviera. A pesar de que México es socio comercial de Estados Unidos, el segundo mayor importador y su mayor proveedor de productos agrícolas y alimentos, Trump amenazaba a México con un impuesto que ponía en jaque la endeble economía mexicana, aun más en un momento en que la disputa por el poder cuestionaba cada acto del nuevo gobierno, por menor que fuera.

En ese contexto el gobierno mexicano inició negociaciones a través de su canciller, Marcelo Ebrard y su equipo, con las autoridades estadounidenses encargadas de economía y comercio de ese país. El plan era lograr un acuerdo que evitara la imposición de aranceles a cambio de contener el flujo migratorio en territorio mexicano. Para algunos, la amenaza no era creíble y por tanto la decisión de ceder ante el chantaje era innecesaria, para otros, se trataba de una extorsión al más puro estilo de la mafia de la que el gobierno mexicano solo podía tratar de minimizar el impacto. La realidad es que el impacto de poner aranceles sobre productos mexicanos podría resultar devastador para la economía del nuevo gobierno y López Obrador cedió, México aceptó ser el filtro migratorio de Estados Unidos.

Tal como lo hemos relatado ningún tema se explica por sí mismo, sino que es importante entender que al mismo tiempo que hubo una reacción muy crítica ante esta decisión, hubo sectores, incluso rivales políticos de López Obrador, 
que calificaron la decisión como prudente y necesaria. Sin embargo, hay un dato que también puede estar detrás de la decisión pragmática que asumió el gobierno mexicano. Aunque México es un país de larga tradición migratoria, la realidad es que no es un país con conciencia de ser una de las naciones de mayor expulsión y flujo de personas del planeta (CONAPO, 2016), esto que sería largo de explicar aquí, se puede entender en la sorpresa que habían causado en la opinión pública mexicana las caravanas de migrantes (finales de 2018 inicios del 2019), como si se tratara de una experiencia inédita en la historia mexicana cuando el flujo migratorio a través del país se ha dado de manera constante y creciente por al menos durante 3 décadas. La única diferencia es que las caravanas buscaron explícitamente visibilizar el éxodo como forma de protección al caminar en grupos numerosos -en medio de un cambio de estafeta política como hemos relatado-, mientras que el flujo tradicional buscó siempre invisibilizar a las personas migrantes para evadir los retenes de control, a la policía migratoria, a los extorsionadores ordinarios y sobre todo, a la delincuencia organizada que durante años ha hecho del flujo migratorio uno de los negocios más rentables de esos grupos delincuenciales, amparados por los poderes políticos estatales y municipales coludidos con los criminales para darles protección y garantizarles impunidad. Un caso emblemático de esta criminalidad es el asesinato de 72 migrantes en 2010 (PASTRANA, 2020).

Un elemento que contribuyó a la decisión de aceptar el reto de detener a los migrantes en territorio mexicano se encuentra en la propia opinión pública mexicana. No hay que olvidar el momento político en que se dio esta amenaza desde Estados Unidos (junio 2019), justo en medio de una cantidad de decisiones, golpeteos y grupos demandantes contra el gobierno. Sobresale el hecho de que en ese mismo periodo se estaba desapareciendo la figura de la Policía Federal (acusada de estar corrompida en su interior), para formar una nueva figura de vigilancia centralizada, la Guardia Nacional, una institución de seguridad militarizada cuyo objetivo es aligerar el clima de violencia que subsiste en el país y proteger a la ciudadanía. De esta forma, además de la economía en peligro y la inseguridad persistente, la mayoría de los mexicanos apoyaba la medida de contener el flujo migratorio e incluso restringir el cruce fronterizo ${ }^{7}$. Este dato por sí mismo no explica la decisión del gobierno de aceptar retener a los migrantes, pero ubicado junto con una cantidad de variables de enorme tensión del momento, ofrecen una variedad de elementos para entender la decisión de asumir "el menor costo político" y no solo la ecuación "Migrantes a cambio de

$761.5 \%$ de los mexicanos declaró en una encuesta a nivel nacional estar de acuerdo con que México les impidiera el paso a los migrantes que intentaran entrar al país sin documentos (MEXICANOS..., 2019). 
Aranceles", como muchos insistieron en reducir el enorme momento de tensión que se dio entre los gobiernos de Estados Unidos y México, a lo largo de la negociación a puerta cerrada en oficinas dentro de la Casa Blanca en Washington, donde los funcionarios mexicanos que asistieron, prácticamente permanecieron sin contacto con el exterior por más de 24 horas -literalmente retenidos- hasta que aceptaron un "acuerdo" para evitar la imposición de aranceles. Lo que por años los internacionalistas han llamado, relación asimétrica entre México y Estados Unidos fue más evidente que nunca pese a años de relación comercial a través del Tratado de Libre Comercio (T.L.C) y la renovación de un nuevo tratado comercial (TMEC), que finalmente se firmó en 2020 pese a las amenazas verbales constantes de parte de Trump. La compleja relación de México con Estados Unidos estaba en una fase de gran tensión tanto por la presión constante del presidente estadounidense desde su campaña electoral -entonces el presidente mexicano era Peńa Nieto-, como por el acento ideológico hacia la izquierda del presidente López Obrador, quien pese a todos los augurios fatalistas de muchos, que esperaban un "choque de trenes entre ambos mandatarios", ambos de convicciones firmes y personalidades fuertes-, no se enganchó en ninguna confrontación con Trump y optó por sobrellevarlo como se hace en las corridas de toros, alzando la capa y dejando pasar a la bestia. A pesar de que esa actitud de mesura ante Trump que le ha evitado tanto a la presidencia mexicana como al país entero mayores problemas de los que de por sí ha tenido al abrir la caja de pandora de la corrupción con todo lo que eso significa, el costo político, social y humanitario lo han pagado los inmigrantes.

El acuerdo para detener la amenaza de aranceles de parte de Estados Unidos fue el despliegue de 150 mil agentes de la Guardia Nacional en 11 municipios de la frontera sur del país (10 de junio de 2019), con la intención explícita de detener a los migrantes que intentaran cruzar sin documentos y minimizar así su llegada a la frontera norte de México y eventual cruce a Estados Unidos, como había ocurrido por décadas. Esta medida ha recibido innumerables críticas, incluso de los propios miembros del equipo más cercano del propio presidente, como es el caso del viejo político de izquierda, Porfirio Muñoz Ledo, quien cuestionó abierta y repetidas veces el uso de este aparato militarizado para atender un asunto humanitario como es la migración.

El problema se agravó cuando a esta medida sumó otra que el gobierno de Estados Unidos había tomado desde enero de 2019 pero que al inicio no tuvo mayores repercusiones, pero al paso de los meses se fue agravando. Se trata del programa "Quédate en México" (Protocolo de Protección a Migrantes, por sus siglas en inglés), que obliga a las personas solicitantes de asilo en Estados Unidos 
a esperar en México la resolución de su audiencia (PARIS POMBO, 2019). Desde entonces, las personas que logran llegar a la frontera norte mexicana, cruzar a Estados Unidos y presentar una solicitud de asilo en ese país, no obtienen la protección de la autoridad estadunidense, sino que deben volver a México y permanecer en este país todo el tiempo necesario para volver a cruzar a Estados Unidos cuando se les indique. Se calcula que en este limbo migratorio se encuentran hasta 40000 personas, muchas de la cuales, aunque consigan una audiencia en una corte migratoria estadounidense, no tienen casos suficientemente fuertes desde la lógica jurídica como para recibir asilo en aquel país, lo que implica que muchos de ellos podrán decidir volver a sus países de origen -cuyas condiciones de violencia, pobreza y desigualdad continúan- o quedarse en México de manera definitiva. Esta es la razón por la que algunos analistas consideran que México ha iniciado una etapa de ser un país principalmente de tránsito migratorio a ser un país de destino (HAAS; SÁCHEZ-MONTIJANO, 2020).

A este asunto lo acompañó el debate sobre la posibilidad de que México, obligado por las circunstancias y la presión del gobierno estadounidense, se convirtiera en un "tercer país seguro" que es una figura jurídica que implica que un país acepta, a cambio de recursos económicos, hacerse cargo del flujo migratorio que acepta permanecer en un país diferente al de su origen y del que planeaban como destino. Turquía es el ejemplo más acabado de esta figura entre los países de África y Asia respecto a Europa. Y aunque el gobierno mexicano rechazó categóricamente esa posibilidad y negó cualquier insinuación de aceptar recibir un pago a cambio de hacerse cargo de manera definitiva del flujo de personas que siguen cruzando de manera continua el país, la realidad es que las fronteras mexicanas albergan a miles de personas en espera de internarse en México (quienes están en el sur), y avanzar hacia Estados Unidos (quienes están en el norte) (AFF, 2020).

A esta situación de los "varados en la frontera" se suma otro grupo que se conforma de casi 149000 personas que son los solicitantes de asilo y refugio en México (acumulados entre 2013 al 2020), de los cuales 20\% han sido aceptados, por lo que solo 29,132 cuentan con la documentación que se requiere para permanecer en el país, el resto experimenta una suerte de "limbo migratorio" a la espera de resolver su situación jurídica. Vale decir que, aunque las nacionalidades de origen de los extranjeros que buscan radicar en México han sido tradicionalmente de países procedentes de Centro América -Guatemala, Honduras, El Salvador, Nicaragua- (PARDO MONTAÑO; DÁVILA, 2019), los últimos años se han incrementado notoriamente los nacionales de Haití, Cuba y sobre todo de Venezuela (GANDINI; LOZANO-ASCENCIO; PRIETO ROSAS, 
2019). Un contingente que sobresale por ser poco común en México, son los extracontinentales que vienen principalmente de Camerún, India y República Democrática del Congo (PRADILLA, 2020).

Ante este panorama, podemos decir que los cambios, ajustes y decisiones en torno a la dinámica migratoria, que se tomaron en el primer periodo (2019) de gobierno, bajo la presidencia de López Obrador, y las declaraciones que a inicios de la nueva presidencia sonaban como un cambio radical en la conducción de la política migratoria mexicana, en realidad fueron tomadas por el pragmatismo que se impuso y el tema migratorio quedó lejos de dar un giro de 180 grados que muchos esperaban ver en un gobierno de izquierda (CALDERÓN CHELIUS, 2018a). Así, las palabras del subsecretario de la Secretaría de Gobernación vía Twitter, Alejandro Encinas, un viejo militante de izquierda y persona comprometida con las causas más nobles como sello de una vida, quedaron en promesa sin cumplir: "Vamos a pasar de una visión de seguridad nacional y de persecución contra migrantes a una visión de derechos humanos. Vamos a dignificar el trabajo del Instituto Nacional de Migración. Las estaciones migratorias no son cárceles" (ENCINAS, 2018).

\section{México como muro}

La decisión de emprender una política migratoria de contención a través de la Guardia Nacional (ente militarizado de reciente creación en el país), así como la estrategia de retener a las personas migrantes en las estaciones migratorias, cuya capacidad muy pronto se desbordó, lo mismo que el abuso de los tiempos legales de espera que las leyes mexicanas acreditan para dicho proceso, dio resultados casi inmediatos. El número de personas que intentaron cruzar la frontera de México con Estados Unidos disminuyó drásticamente, las capturas por la Guardia Fronteriza de Estados Unidos se redujeron, no sólo por la estrategia mexicana sino también por el incremento de detención de niños y niñas separados de sus padres al intentar cruzar la frontera como parte de la política migratoria estadounidense llamada Tolerancia Cero. Del lado mexicano aumentó el número de deportaciones "exprés” y en menos de un mes de iniciado el programa acordado con la autoridad estadunidense -junio a julio de 2019-, se deportaron a $79.3 \%$ de los extranjeros que entraron al país, aludiendo un retorno asistido solicitado por las propias personas en tránsito. Los cambios en la estrategia de parte de Estados Unidos modificaron a su vez los flujos migratorios lo que llevó a que distintas ciudades fronterizas del lado mexicano se volvieran "ciudades de espera", como ocurrió con Ciudad Juárez, Piedras Negras, Nuevo 
Laredo entre otras, donde la dinámica poblacional cambió drásticamente en tan sólo un año (MALKIN, 2019).

En la parte que corresponde al sur del país, la detención de migrantes, sobre todo los contingentes de personas provenientes de distintos países de África, Cuba y Haití, fueron retenidos en su intento de cruce hacia el norte de México y al cabo de varios días, sin mayor información ni posibilidad de movilidad, empezaron a darse disturbios que ocasionaron crisis nerviosa, lesiones menores, así como la fuga de varios (incluso en miles) de los detenidos que, como lo describió la policía migratoria mexicana, "escapaban" de la autoridad. Sin embargo, de acuerdo a las leyes mexicanas la migración indocumentada es solo una falta administrativa y no acredita la prisión preventiva (desde 2008), además, los tiempos de revisión de las condiciones jurídicas de las personas se rebasan constantemente, lo que provoca hacinamiento, escases de insumos y condiciones precarias en las estaciones migratorias y los albergues que la autoridad ha desplegado tanto al sur como al norte del país, pues la cantidad de personas así como los diversos perfiles (familias junto con personas solas, niños, adultos, personas con distintas preferencias sexuales), generan espacios de convivencia muy complejos, lo que se agravó con el impedimento explícito de parte del Instituto Nacional de Migración (INM), de permitir el acceso de defensores de derechos humanos a las estaciones migratorias a fin de acompañar los casos de las personas retenidas y observar las condiciones de dichos lugares (AMNISTÍA INTERNACIONAL, 2020).

Esta decisión en nada se diferencia de la política migratoria que los gobiernos mexicanos anteriores siguieron anteriormente por años y por el contrario, aún con un acuerdo tan lacerante para las personas migrantes como el aceptado por el gobierno de López Obrador a través de la cancillería, no se dieron cambios en las políticas humanitarias de atención, centradas en el bien de las personas y la comprensión de las necesidades que orillan a la decisión de migrar, como se anunció al inicio del nuevo gobierno. Lo que destaca es que más allá del discurso presidencial e incluso de la voluntad de sus colaboradores más cercanos, lo que se constata es la sobrevivencia de la maquinaria de control migratorio que tiene su propia lógica, su ética y práctica que no ha cambiado al interior ni ha sido redefinida, como se prometió que se haría, considerando que el Instituto Nacional de Migración es una de las entidades peor evaluada por la opinión pública mexicana (WOLF, 2013) o como lo ha señalado reiteradamente el sacerdote defensor de migrantes, Alejandro Solalinde, "El INAMI está podrido" (mayo 2019). 


\section{La sociedad Civil pro migrante y AMLO}

No podría haber fecha más significativa para hacer un balance de la política migratoria en tiempos del gobierno de Andrés Manuel López Obrador que en el $10^{\circ}$ aniversario del asesinato de 72 personas migrantes secuestradas en el rancho de San Fernando, Tamaulipas, México (TURATI, 2016). La impunidad ante este crimen de lesa humanidad pendiente de justicia y de resarcirse el daño en lo posible, desde el gobierno de Felipe Calderón Hinojosa (20102012) cuando ocurrió el hecho, todo el periodo presidencial de Enrique Peña Nieto (2012-2018) y el tiempo que lleva en el poder López Obrador (2018 a la fecha), movilizó a la gran mayoría de las organizaciones de la sociedad civil que trabajan con las personas migrantes en México desde hace años (CALDERÓN CHELIUS, 2016), para demandar no solo la atención de este caso y su reparación integra, sino incluso, un viraje a la política migratoria a la que algunos miembros del Consejo Consultivo del propio Instituto Nacional de Migración calificaron de "simulación y sobre todo, de actuar a favor de Estados Unidos externalizando las fronteras de ese país hasta el territorio mexicano a través de la Guardia Nacional que actúa como el muro que tantas veces prometió Trump a sus electores" (HEREDIA; SAIZ VALENZUELA; ZAMUDIO GRAVE; ZARAGOZA GONZÁLEZ, 2020).

Esta postura dura y directa contra la política migratoria de parte de dichos consejeros es resultado de lo que se percibe en general entre los activistas y estudiosos del proceso migratorio como una incongruencia ante la promesa inicial de hacer un cambio radical en la política migratoria mexicana y lo que se fue dando al paso de los meses en un gobierno de izquierda, tal como lo hemos relatado a lo largo de estas páginas (SOLIS, 2019). Pero el desencuentro entre las organizaciones de la sociedad civil y el presidente y su gabinete no se dio sólo por lo que fue pasando a lo largo de esos meses y las distintas decisiones, en realidad, se dio al poco tiempo de iniciado el nuevo gobierno y va más allá de la causa migratoria. López Obrador tiene una concepción de la sociedad civil como grupos que, ante la ausencia de la acción del estado en temas como la pobreza, la desigualdad, la violencia, o la migración en este caso, han reemplazado la obligación que el estado tiene para hacerse cargo de estos asuntos. De alguna manera eso es cierto dado que desde el ascenso de la derecha al poder a través del Partido Acción Nacional (P.A.N), que ganó la presidencia en el año 2000, hubo un incremento de organizaciones de la sociedad civil que efectivamente ocuparon el espacio que el gobierno decidió no atender directamente e incluso, dejó a si suerte. Ante ese vacío de acción de los distintos gobiernos, algunas organizacio- 
nes y sobre todo algunos de sus líderes se volvieron interlocutores directos del propio estado, beneficiarias directas del presupuesto y entes de interés al interior de los distintos sectores del gobierno, muchas veces más que como equilibrio, sino como claro apoyo a las medidas adoptadas por el gobernante en turno ${ }^{8}$. Sin embargo, esa visión de parte del presidente respecto a la "élite de las organizaciones de la sociedad civil”, incluyó y generalizó sobre la inmensa mayoría de las organizaciones cuando gran parte de ellas suelen componerse de activistas solidarios, gente de base, jóvenes profesionistas inspirados por el discurso a favor de los más necesitados e incluso, misioneros (laicos y religiosos), fuertemente inspirados en el credo de apoyo a los desposeídos que es el mismo discurso que López Obrador reivindica. Para el caso de las organizaciones pro migrantes en México, eso es clarísimo a la vez que explica el ascenso de liderazgos religiosos a través de figuras como el padre Alejandro Solalinde, Pedro Pantoja, Raúl Vera (q.e.p.d), entre muchos otros (COLEF, 2020). La descalificación y reducción de apoyos de esta forma de hacer política (las O.N.Gs) en paralelo al propio estado, se volvió un tema recurrente de parte de López Obrador desde el inicio de su gestión y una forma de subordinar a los liderazgos que existen fuera del contexto de su propio equipo. Esto generó un fuerte recelo y reacción de gran parte de estas organizaciones que, en lugar de volverse aliadas del nuevo gobierno, se volvieron opositores. Otros miembros de su gabinete no comparten esa visión en este tema pues reconocen el trabajo de estas organizaciones que efectivamente durante años hicieron lo que el propio estado se desentendió de resolver en temas como vivienda, albergues, comida, construcciones, servicios, etc.

El desencuentro entre el ejecutivo y muchas de estas Organizaciones de las sociedad civil en el caso de las que trabajan temas migratorios se incrementó con la falta de financiamiento de parte del estado del cual dependían, del cambio de interlocutores en cada uno de los temas de la agenda política del nuevo gobierno que los desbancó, pero sobre todo, ante las decisiones que, en materia migratoria, el gobierno mexicano fue tomando, como el hecho de negociar salvar al país de aranceles a cambio de desplegar a la Guardia Nacional para retener a los migrantes en tránsito, por mencionar un ejemplo que hemos reseñado a profundidad. Para las organizaciones y en general para los analistas, el gobierno no tendría que haber optado por evitar los aranceles, sino que se tendría que

\footnotetext{
8 Sería imposible abrir este tema en este espacio, pero claramente hay organizaciones de la sociedad civil que por años fungieron como el brazo "civil" de las decisiones y acciones de los gobiernos que incluso avalaron medidas draconianas contra los sectores más empobrecidos, de seguridad que encubrían la violencia, de combate a la corrupción que omitían lo obvio y de pretendido apoyo a la educación en pro del negocio educativo en sustitución de la educación gratuita. Para el tema migratorio hay las que incluso recibieron presupuestos por encima de la oficina encargada de atender a la comunidad mexicana radicada en el extranjero.
} 
haber decidido por apoyar a los migrantes en su ingreso, tránsito y eventual cruce hacia Estados Unidos a costa del precio que se tuviera que pagar como país, lo que en un discurso humanitario esto sería lo aceptable. La evidencia mostró sin embargo que, aunque López Obrador es un presidente de izquierda y de fuertes convicciones, resultó pragmático y decidido a que su gobierno salga adelante, incluso sacrificando popularidad en temas como el migratorio que, como dijimos antes, tampoco es un tema que genere, desafortunadamente, gran movilización popular a su favor.

Eso profundizó el desencuentro a lo que se suma el hecho de que las organizaciones de la sociedad civil no parecen haber encontrado el modo apropiado de acercarse al gobierno desde una lógica diferente a la que tuvieron durante años cuando la mayoría eran críticas permanentes a las acciones gubernamentales. Tal parece que, al cambio de un gobierno radicalmente distinto, continúan en ese papel de oposición sin lograr serlo -porque la oposición es la derecha ideológicamente hablando-, pero tampoco logran ser incluidas como parte del mapa político que hoy tiene el poder en el país. Es probable que la visión con la que muchos grupos atendieron el tema migratorio requiera una nueva perspectiva no sólo desde el acompañamiento a las personas migrantes como lo han hecho por años, sino insertando la causa pro migrante a demandas muy sentidas en la sociedad mexicana, como la violencia, las desapariciones forzadas, la trata de personas, la impunidad, la justicia y el ataque frontal a la corrupción. Ubicar el tema migratorio como un problema por sí mismo o reducirlo al tránsito o la espera, como predomina en el debate de activistas y militantes de esta causa, lo ha aislado de las grandes problemáticas que el gobierno (que no es solo el presidente), ha decidido atacar de manera decidida, lo que se podría aprovechar, aun con sus contradicciones.

Otro punto de difícil comprensión y consideración como una variable determinante es que gran parte de la complejidad del tema migratorio en México es resultado de las propias sociedades de origen de los migrantes de las que se hace y dice poco en el país. Aunque hubo una apuesta por "desarrollar" Centroamérica, parece que ese proyecto es a muy largo plazo y esa no puede ser la única opción para que las condiciones de violencia y pobreza estructural sigan literalmente expulsando a su población y que México siga recibiéndolos en las mismas condiciones de pobreza, sin demasiadas opciones que ayudarlos a llegar a la frontera norte y eventualmente cruzar a Estados Unidos. Lo mismo pasa respecto a un factor determinante como es el peso que tiene el gobierno estadunidense sobre el gobierno mexicano a quien impone el ritmo y las acciones, aunque la retórica nacionalista insista en decir que México está fuera de su órbita 
de control. La realidad es que muchas de las apuestas política de López Obrador al interior de México dependen de mantener cierto equilibrio respecto al gobierno estadunidense y no abrir un frente que complique aún más la situación del país -más allá de que gobierne dicho país-. No se trata de aceptar como destino esta asimetría, sino entender el juego que está detrás de ciertas decisiones y en su caso, para las organizaciones de la sociedad civil, reconocer esas coordenadas para entender los límites que hay para negociar y buscar el beneficio de las personas migrantes aun en condiciones de subordinación internacional, como es la realidad mexicana respecto a Estados Unidos.

Las organizaciones de la sociedad civil tienen un peso importante para la solución de muchos problemas y deben recuperar su capacidad de interlocución, pero no desde el lugar que tuvieron por años, incluso décadas, sino buscando un lugar desde el cual no busquen suplir, ser la ruta o descalificar toda acción, más bien tratando de descifrar los nuevos códigos que a su vez se van inventando en el camino porque el nuevo gobierno tampoco tiene muy claro que relación establecer con cada grupo y sector social -aunque claramente tiene temas prioritarios, por ejemplo, resolver el tema de las desapariciones forzadas y la violencia criminal (en el tema de los migrantes la trata de personas) ante lo que las organizaciones podrían dar el primer paso y modificar el tipo de relación que aprendieron a construir durante años, cuando lo central es el apoyo a la sociedad civil que representan.

\section{Conclusiones}

Ante la irrupción de la pandemia del COVID-19 todo plan se modificó, requirió repensarse y las coordenadas de trabajo se modificaron en México y en el mundo entero. Las prioridades tomaron un nuevo espacio y algunos temas que no eran parte de la agenda principal, como la salud pública, han obligado al mundo entero a considerarla. Para el tema migratorio en México la pandemia significó un golpe durísimo porque implicó el cierre de espacios de albergue para las personas migrantes, la deportación de miles de personas e incluso, el desalojo de las estaciones migratorias, no como una respuesta a la demanda de las organizaciones de la sociedad civil de no hacer esos espacios lugares de detención ilegal, sino para resolver la coyuntura pandémica. Un hecho a considerar es que el cierre de fronteras de los países de la región centroamericana complicó aún más el retorno de las personas de esos países y por un periodo prácticamente detuvo el flujo migratorio (México nunca cerró sus fronteras). La expectativa es que al iniciarse de manera gradual la apertura y movilidad generalizada en 
la región, el flujo se incremente y con esto se dé una llegada en tropel de miles de personas que han pospuesto su decisión de huir de sus países, sea que logren llegar a Estados Unidos o que decidan quedarse en México.

El escenario político en Estados Unidos es un factor central para definir una política migratoria en México, no porque cambie mucho entre republicanos y demócratas, pero sí porque la estridencia de Donald Trump ha sido muy dañina para la relación bilateral. Las decisiones radicales que dicho personaje ha tomado de manera unilateral han afectado enormemente los proyecto que en México se pensaba se podrían resolver -como permitir la llegada de migrantes e incluso incorporarlas al mercado laboral mexicano- y lo único que el gobierno mexicano ha podido hacer es acoplarse a ellos tratando más que resolver la situación, pagando el menor costo político por las decisiones y estrategias.

Este texto ha pretendido ofrecer una visión amplia, como un vuelo de pájaro, para mostrar algunos de los elementos que explican la política migratoria del gobierno mexicano encabezado por López Obrador que pese a ser un gobierno de izquierda, con planteamientos humanitarios y decidido a atender a los más necesitados -aún a costa de afectar a otros sectores-, en lo migratorio no se apega a esos principios y de alguna manera, ha sido tan pragmático como otros gobiernos. Las coordenadas aquí planteadas pretenden ofrecer una serie de elementos para acompańar el relato del periodo analizado y darle mayor coherencia explicativa a un proceso que no puede verse como algo que ocurre en paralelo a la propia dinámica política y social de un momento de gran efervescencia política en el país. Lo que pasa en México, en el gobierno y entre los distintos actores políticos, ya sean las decisiones, las luchas internas, los temas de la agenda, las visiones del país que se quiere, definen en gran parte el lugar en el que se ubica la política migratoria actual. Insistir en que López Obrador falló a su promesa inicial es desconocer que el proyecto de nación que este político de larga trayectoria planea para el país -que finalmente pudo gobernar por la vía electoral-, no incluye a los inmigrantes, y ahí está el mayor reto para el resto de los actores sociales comprometidos con el tema, buscar ampliar la visión del país que somos desde nuevas coordenadas creativas que ofrezcan una idea de patria inclusiva. 


\section{BIBLIOGRAFÍA}

ALIANZA FRONTERIZA DE FILANTROPÍA [AFF]. La crisis humanitaria en la frontera. San Diego, 11 mar. 2020. Disponible en: https://www.alianza fronteriza.org/crisishumanitaria.html. Acceso en: 30 ago. 2021.

AMNISTÍA INTERNACIONAL. México: Amnístia Internacional exige claridad y garantías sobre el acceso de ONGs a estaciones migratorias. Ciudad de Mexico, 29 ene. 2020. Disponible en: https://www.amnesty.org/es/latest/news/2020/01/mexicoamnistia-exige-claridad-sobre-acceso-ongs-estaciones-migratorias/. Acceso en: 30 ago. 2021.

CALDERÓN CHELIUS, L. Nuevas formas de migrar: las caravanas que avanzan. Gaceta Universitaria, México, n. 270, p. 9-12, feb. 2019. Disponible en: https:// www.politicas.unam.mx/gacetas/gaceta270.pdf. Acceso en: 30 ago. 2021.

CALDERÓN CHELIUS, L. AMLO ante el desafío migratorio. El Universal, Mexico, 7 dic. 2018a. Disponible en: https:/www.eluniversal.com.mx/columna/ leticia-calderon-chelius/nacion/amlo-ante-el-desafio-migratorio. Acceso en: 30 ago. 2021.

CALDERÓN CHELIUS, L. La hospitalidad imaginada o de cómo podemos construir una ciudad hospitalaria sin exaltar los mitos que nos dieron patria. México: Sin Fronteras I.A.P., 2018b. Disponible en: https://sinfronteras.org.mx/ wp-content/uploads/2018/12/Hospitalidad-4-1.pdf. Acceso en: 30 ago. 2021.

CALDERÓN CHELIUS, L. La sociedad civil organizada ante la migración en tránsito en México. México: CANAMID, 2016. (Policy Brief Series, 13.). Disponible en: http://www.canamid.org/descargas/policies/canamid-pb013-es.pdf. Acceso en: 30 ago. 2021.

COLEGIO DE LA FRONTERA NORTE [COLEF]. Migrantes en albergues en las ciudades fronterizas del norte de México. México: COLEF, 2020. Disponible en: https://www.colef.mx/estudiosdeelcolef/migrantes-en-albergues-en-las-ciudadesfronterizas-del-norte-de-mexico/. Acceso en: 31 ago. 2021

CONSEJO NACIONAL DE POBLACIÓN [CONAPO]. Prontuario sobre movilidad y migración internacional, dimensiones de un fenómeno en México. México: SEGOB, 2016. Disponible en: https:/www.gob.mx/cms/uploads/ attachment/file/192258/Prontuario_movilidad_y_migraci_n_internacional_Parte1. pdf. Acceso en: 30 ago. 2021.

ENCINAS, A. Vamos a pasar [...]. [s.l.], 24 ago. 2018. Twitter: @A_Encinas_R. Disponible en: https://twitter.com/a_encinas_r/status/1033033875428175872?ref_ src=twsrc\%5Etfw\&lang=bn. Acceso en: 30 ago. 2021. 
FERNÁNDEZ DE LA REGUERA, A.; GANDINI, L.; GUTIÉRREZ LÓPEZ, E. E.; NARVÁES GUTIÉRREZ, J. C. Caravanas migrantes: las respuestas de México. México: UNAM, 2019. Disponible en: https://archivos.juridicas.unam.mx/www/bjv/ libros/12/5804/8.pdf. Acceso en: 30 ago. 2021.

GANDINI, L.; LOZANO-ASCENCIO, F.; PRIETO ROSAS, V. Crisis y migración venezolana: entre la desprotección y la seguridad jurídica en Latinoamérica. México: UNAM, 2019. Disponible en: https://www.researchgate.net/ publication/339663432_Crisis_y_migracion_de_poblacion_venezolana_Entre_la_ desproteccion_y_la_seguridad_juridica_en_Latinoamerica. Acceso en: 30 ago. 2021.

HAAS, A.; SÁNCHEZ-MONTIJANO, E. México, un país de destino de migrantes, NEXOS, 19 ago. 2020. Disponible en: https://migracion.nexos.com.mx/author/ alexandra-haas/. Acceso en: 30 ago. 2021.

HEREDIA, C.; SAIZ VALENZUELA, A. M.; ZAMUDIO GRAVE, P.; ZARAGOZA GONZÁLEZ, M. Exigen alto a la simulación en política migratoria. Sin Fronteras IAP, Mexico, 25 ago. 2020. Disponible en: https://sinfronteras.org. mx/exigen-alto-a-la-simulacion-en-la-politica-migratoria/. Acceso en: 30 ago. 2021.

\section{NG, J. J.; SERRANO, C. 98,470 votos de mexicanos desde el extranjero en} 2018, 140\% más que en 2012. México: BBVA Research, 2018. Disponible en: https:/www.bbvaresearch.com/wp-content/uploads/2018/07/VotoMexicanosdel Exterior_20180716.pdf. Acceso en: 30 ago. 2021.

LÓPEZ OBRADOR, A. M. Oye Trump. México: Planeta, 2017.

MALKIN, E. Las ciudades fronterizas se convierten en el destino final de los migrantes. The New York Times, New York, 8 ago. 2019. Sección México. Disponible en: https://www.nytimes.com/es/2019/08/08/espanol/america-latina/ciudad-juarezmigrantes.html. Acceso en: 30 ago. 2021.

MEXICANOS piden endurecer política migratoria: encuesta. El Universal, Mexico, 12 jun. 2019. Disponible en: https://www.eluniversal.com.mx/nacion/mexicanosquieren-que-se-impida-paso-de-migrantes. Acceso en: 30 ago. 2021.

PARDO MONTAÑO, M.; DÁVILA, C. A. Más allá de la emigración: presencia de la población extranjera residente en México. México: UNAM, 2019. Disponible en: https://www.researchgate.net/publication/336968001_Mas_alla_de_la_emigracion_ Presencia_de_la_poblacion_extranjera_residente_en_Mexico. Acceso en: 30 ago. 2021.

PARIS POMBO, D. Que significa el programa "Quédate en México" y en que difiera de "México como tercer país seguro". Boletín COLEF, 2019. Disponible en: https:// 
www.colef.mx/noticia/que-significa-el-programa-quedate-en-mexico-y-en-que-difierede-mexico-como-tercer-pais-seguro/. Acceso en: 30 ago. 2021.

PASTRANA, D. \#72migrantes: 10 años de lucha por la verdad. Pie de Página, Mexico, 22 ago. 2020. Disponible en: https://piedepagina.mx/72-migrantes-10-anosde-lucha-por-la-verdad/. Acceso en: 30 ago. 2021.

PRADILlA, A. Migrantes de otro mundo. Animal Político, 2020. Disponible en: https://www.animalpolitico.com/migrantes-de-otro-mundo/. Acceso en: 30 ago. 2021.

RUIZ PARRA, E. Solalinde. Gatopardo, 19 sept. 2011. Disponible en: https:// gatopardo.com/reportajes/alejandro-solalinde/. Acceso en: 30 ago. 2021.

SOLICITUDES de refugio en México, diseñadas para rechazar a migrantes: La 72. Aristegui Noticias, La 72. 2015. Disponible en: https://aristeguinoticias.com/2206/ mexico/solicitudes-de-refugio-en-mexico-disenadas-para-rechazar-a-migrantes-la-72/ Acceso en: 31 de agosto 2021.

SOLIS, C. El INAMI esta podrido: Solalinde. Diario del Sur, Tapachula, 22 may. 2019. Disponible en: https://www.diariodelsur.com.mx/local/el-inami-esta-podridosolalinde-migracion-migrantes-corrupcion-derechos-humanos-activistas-abuso-deautoridad-3656834.html. Acceso en: 31 ago. 2021.

TURATI, M. \#Másde72, echando luz a las fosas, Pie de página, Mexico, 2016. Disponible en: https://enelcamino.piedepagina.mx/ruta/masde72-echando-luz-alas-fosas/. Acceso en: 30 ago. 2021.

VARELA, A. La transmigración que nos obliga a imaginarnos como país de acogida. Animal Político, 25 ene. 2019. Sección Plumaje. Disponible en: https:// www.animalpolitico.com/diversidades-fluidas/la-transmigracion-que-nos-obligar-aimaginarnos-como-pais-de-acogida/. Acceso en: 30 ago. 2021.

WOLF, S. Diagnóstico del Instituto Nacional de Migración: Hacia un sistema de rendición de cuentas en pro de los derechos de las personas migrantes en México. México: Insyde, 2013. Disponible en: http://insyde.org.mx/pdf/informes/ Diagnostico-INM_Resumen-Ejecutivo_Español.pdf. Acceso en: 30 ago. 2021.

Recebido em: 31 de agosto de 2020

Aprovado em: 23 de novembro de 2020 